Unfortunately we are no longer included in orthopaedics ranking which is a pity and Nature Publishing Group is trying to do something about this. At the present time we are only ranked amongst Clinical Neurological journals.

\section{Spinal Cord Prize}

The closing date for the next Spinal Cord Prize is 28th February 2003. Please encourage all your medical staff under the age of 39 to submit an article for this important valuable prize.

\section{New Referees}

We are always in need of new referees. Please let me have any names and addresses of people that you think

\section{Editorial Notice}

Spinal Cord (2002) 40, 625. doi:10.1038/sj.sc.3101412

\section{Spinal research news}

There are innumerable meetings and conferences on the spinal cord. So many that it is not surprising or unusual to find that many members of the various groups are largely unaware of the work which is being carried out by other groups.

I hope to have a frequent but not regular update on research and development in this field. This will consist mostly of reports of meetings or conferences of both clinical and basic research. It is essential for might be suitable to act as referees for the Journal, together with their field of special interest.

\section{Help with English Language}

Many of the manuscripts that we receive are written in poor English. This is particularly the case when manuscripts come from less developed countries. If any member of the Society would like to help with the preparation and editing of such manuscripts, please let me know and I will put them in touch with the appropriate authors. This service would be of immense benefit to many of our members.

LS Illis

clinicians to keep abreast of basic research since lack of awareness can only lead to lost opportunities for interactions and collaborations, and this is particularly important at the present time when the possibility of basic research being translated to the clinical field is likely to occur within the next few years.

Any member of ISCoS who has attended an interesting conference may submit a report for consideration. 